\title{
Comparison of Unidirectional Barbed Suture Compared to Conventional Braided Suture at the Time of Cesarean Section
}

\author{
Vivina A Napier ${ }^{1,2}$, Rachel E Warwar ${ }^{1}$, Logan M Havemann ${ }^{1}$, Keith A Watson ${ }^{1}$, Austin D Findley ${ }^{1,2}$, Rose A \\ Maxwell ${ }^{1}$ and Steven R Lindheim ${ }^{1 *}$ \\ ${ }^{1}$ Department of Obstetrics and Gynecology, Wright State University, USA \\ ${ }^{2}$ Wright -Patterson Air Force Base Medical Center, USA
}

Submission: January 04, 2017; Published: January 30, 2017

*Corresponding author: Steven R MD, MMM, 128 Apple Street, Suite 3800 Weber CHE, Dayton, OH, USA 45409, Tel: (937) 208-2301; Fax: (937) 222-7255; Email: steven.lindheim@wright.edu

\section{Abstract}

Background: The bidirectional barbed suture has been reported as effective as conventional suture in various soft-tissue closure sites The objective of this manuscript is to evaluate peri- and postoperative outcomes using a Unidirectional Barbed Suture (UBS) compared to Conventional Braided Suture (CBS) at time of Cesarean section closure.

Methods: This retrospective study evaluated women $(\mathrm{n}=138)$ undergoing cesarean delivery with either UBS using the V-Loc ${ }^{\mathrm{TM}}$ wound closure device (Covidien) $(\mathrm{n}=106)$ or CBS (Vicryl ${ }^{\circledR}$, Ethicon) $(\mathrm{n}=32)$ by a single practice. Outcomes measured included operative time; estimated (EBL) and objective blood loss; hospital stay; and peri-, postoperative, and overall complications. Deliveries prior to 28 weeks gestational age and women $<18$ years of age were excluded. Student's t-test and chi-square were used for data analysis. A p-value $<0.05$ was considered significant.

Results: Operative time for the UBS group was similar to the CBS group ( $35.0 \mathrm{~min}$ vs. $35.91 \mathrm{~min}$; $\mathrm{p}=0.69$ ), as was EBL ( $572 \mathrm{~mL}$ vs $625 \mathrm{~mL}$ $\mathrm{p}=0.51$ ); change in hemoglobin ( $1.8 \mathrm{~g} / \mathrm{dL}$ vs $1.7 \mathrm{~g} / \mathrm{dL}, \mathrm{p}=0.84)$; hospital stay ( $3.25 \mathrm{~d}$ vs $3.19 \mathrm{~d}, \mathrm{p}=0.63)$; and overall complications $(19.8 \%$, $\mathrm{n}=21$ vs $12 \%, \mathrm{n}=4, \mathrm{p}=0.35$ ).

Conclusion: UBS is not inferior to CBS at the time of Cesarean section closure with respect to operative time, blood loss, or complications, and may be considered as an adjunctive suture in the closure of the Cesarean incision given the equal safety and efficacy.

Keywords: Barbed suture; Hysterotomy; Cesarean section; V-Loc ${ }^{\mathrm{TM}}$

Synopsis: Unidirectional barbed suture is not inferior to conventional braided suture at the time of cesarean closure with respect to operative time, blood loss or complications.

Abbreviations: UBS: Unidirectional Braided Suture; CBS: Conventional Braided Suture; BMI: Body Mass Index; EBL: Estimated Blood Loss

\section{Background}

The Quill bidirectional barbed suture was approved by the United States Food and Drug Administration for soft tissue approximation in 2004. Since then, there has been reported use of this and other barbed sutures during surgical and gynecologic procedures. Recent studies have found the barbed suture is an effective method of soft tissue closure with non-inferior results to conventional closure methods with respect to gynecologic procedures. This has been demonstrated in the setting of closure of the hysterotomy site during laparoscopic myomectomies[1], closure of the vaginal cuff in laparoscopic hysterectomies [2] and closure of skin incisions during Cesarean section [3] with respect to operative times, estimated blood loss, length of hospital stay and perioperative complications [1-3].

Except for limited study of its use in bovine Cesarean sections [4], there have been no studies to evaluate the safety, perioperative outcomes and efficacy of the barbed suture for closure of the hysterotomy, peritoneal, fascial incision, subcutaneous tissue and skin at the time of Cesarean section on human subjects. Thus, the purpose of this study was to assess outcomes related to the use of Unidirectional Barbed Suture (UBS) with respect to safety and efficacy compared to Conventional Braided Suture (CBS) at the time of Cesarean section. 


\section{Methods}

This retrospective study was reviewed and approved by the Wright State University, Miami Valley Hospital and United States Air Force Institutional Review Boards and was in compliance with the privacy-act guidelines. Informed consent was not required for this study.

This was a retrospective cohort study of 135 patients who underwent Cesarean section from January 2008-October 2013 by a single practitioner at Miami Valley Hospital in Dayton, Ohio. Patients who underwent Cesarean section with a Pfannenstiel skin incision using UBS were compared with the patients who underwent Cesarean section with closure using CBS. Given a single practice, the surgeon primarily used the V-loc suture and therefore less control subjects were studied in the given time frame.

Patients under the age of 18 were excluded due to local IRB requirements and those undergoing delivery at less than 28 weeks gestational age were excluded from the analysis, presumably because these patients underwent a classical incision during the Cesarean delivery.

All procedures were performed in the same standard fashion using a Pfannensteil incision. All hysterotomies were performed in a transverse fashion through the lower uterine segment. After delivery of the infant, the placenta was allowed to deliver with gentle cord traction, and the uterus was exteriorized. For the CBS group, the hysterotomy was repaired within a single layer with 0-Vicryl ${ }^{\circledR}$ (Ethicon) in a running locked fashion. Additional suture was used at the surgeon's discretion to imbricate the initial closure or to achieve hemostasis. The peritoneum was closed with 2-0 Vicryl ${ }^{\circledR}$ at the discretion of the surgeon and the

\section{Results}

Table 1: Patient Demographics.

\begin{tabular}{|c|c|c|c|}
\hline & $\begin{array}{c}\text { Unidirectional Barbed Suture } \\
(\mathrm{n}=106)\end{array}$ & $\begin{array}{c}\text { Conventional Braided Suture } \\
(\mathrm{n}=32)\end{array}$ & p-value \\
\hline Age $(\mathrm{yrs})^{1}$ & $26.1+/-5.2^{2}$ & $28.2+/-5.7$ & NS \\
\hline BMI $(\mathrm{kg} / \mathrm{m})^{1}$ & $35.7+/-7.5$ & $32.5+/-6.9$ & NS \\
\hline Infant Weight $(\mathrm{gms})^{1}$ & $3326+/-654$ & $3266+/-737$ & NS \\
\hline Macrosomia & $10.8 \%(11)$ & $9.4 \%(3)$ & NS \\
\hline Primary Cesarean & $51 \%(52)$ & $42.4 \%(14)$ & NS \\
\hline Repeat Cesarean & $49 \%(51)$ & $57.6 \%(18)$ & NS \\
\hline Routine Cesarean & $69.6 \%(72)$ & $72.7 \%(23)$ & NS \\
\hline Urgent Cesarean & $22.5 \%(23)$ & $18.2 \%(6)$ & NS \\
\hline Emergent Cesarean & $7.8 \%(8)$ & $9.1 \%(3)$ & NS \\
\hline Epidural Anesthesia & $22.9 \%(23)$ & $12.5 \%(4)$ & NS \\
\hline Spinal Anesthesia & $72.5 \%(74)$ & $81.3 \%(26)$ & NS \\
\hline General Anesthesia & $4.9 \%(9)$ & $6.3 \%(2)$ & $100 \%(33)$ \\
\hline Singleton Gestation & $95.1 \%(97)$ & & NS \\
\hline
\end{tabular}


Journal of Gynecology and Women's Health

\begin{tabular}{|c|c|c|c|}
\hline Multiple Gestation & $4.9 \%(5)$ & $0 \%(0)$ & NS \\
\hline Cephalic Presentation & $85 \%(88)$ & $78 \%(25)$ & NS \\
\hline Polyhydramnios & $0 \%(0)$ & $0 \%(0)$ & NS \\
\hline Anticoagulation & $2.8 \%(3)$ & $0 \%(0)$ & NS \\
\hline BTL performed & $19 \%(21)$ & $21.2 \%(6)$ & NS \\
\hline
\end{tabular}

${ }^{1}$ Mean

${ }^{2}+/$ - Standard Deviation

There were 142 patients that underwent Cesarean section in the specified time period. Fourpatients met exclusion criteria. Patient demographic data are given in (Table 1). There were no differences between the UBS $(n=106)$ and CBS $(n=32)$ groups with respect to patient age $(26.1+/-5.2$ vs $28.2+/-5.7$, p-NS $)$ and BMI $(35.7+/-7.5$ vs $32.5+/-6.9$, p-NS $)$ nor were there differences in the number of repeat Cesarean sections (49\% vs $57.6 \%$, p-NS), or the number that underwent general anesthesia (4.9\% vs $6.3 \%$, p-NS), multiple gestation, or on anticoagulation.

Those undergoing tubal ligation at the time of surgery was similar between groups (19\% vs $21.2 \%$, p-NS).

Peri-operative outcomes between the UBS and the CBS groups are given in Table 2. There were no significant differences in the total operative times (UBS-35.0 minutes vs. CBS-35.91 minutes, p-NS); closure times (30.2 minutes vs. 31.67 minutes, p-NS); estimated blood loss (572 mL vs $626 \mathrm{~mL}$, p-NS) or decrease in hemoglobin (1.8 g/dL vs $1.7 \mathrm{~g} / \mathrm{dL}, \mathrm{p}-\mathrm{NS})$; or length of hospital stay (3.25d vs 3.19d, p-NS) (Table 2).

Table 2: Peri-operative Outcomes.

\begin{tabular}{|c|c|c|c|}
\hline Outcome & $\begin{array}{c}\text { Unidirectional Barbed Suture } \\
(\mathbf{n = 1 0 6})\end{array}$ & $\begin{array}{c}\text { Conventional Braided Suture } \\
(\mathbf{n = 3 2})\end{array}$ & p-NS-value \\
\hline Total Operative Time, minutes & $35.0+/-11.6$ & $35.909+/-7.91$ & NS \\
\hline Closure Time, minutes & $30.3+/-10.9$ & $31.67+/-7.74$ & NS \\
\hline Estimated Blood Loss, mL & $572.1+/-187$ & $625.8+/-1987.7$ & NS \\
\hline Change in Hgb, g/dL & $1.8+/-0.92$ & $1.7+/-1.24$ & NS \\
\hline Hospital Stay, d & $3.25+/-0.6$ & $3.19+/-0.6$ & NS \\
\hline
\end{tabular}

Table 3: Postoperative Outcome.

\begin{tabular}{|c|c|c|c|}
\hline Postoperative Outcome & $\begin{array}{c}\text { Unidirectional Barbed Suture } \\
(\mathbf{n = 1 0 6})\end{array}$ & $\begin{array}{c}\text { Conventional Braided Suture } \\
(\mathbf{n = 3 2})\end{array}$ & p-value \\
\hline Overall Complications & $19.8 \%(21)$ & $12 \%(4)$ & NS \\
\hline Intra-operative Complications & $4.8 \%(5)$ & $3 \%(1)$ & NS \\
\hline Post-operative Complications & $15.1 \%(16)$ & $9.4 \%(3)$ & NS \\
\hline Transfusion & $2 \%(2)$ & $0 \%(0)$ & NS \\
\hline Cellulitis & $2.9 \%(3)$ & $3 \%(1)$ & NS \\
\hline Seroma, Hematoma & $6.7 \%(7)$ & $6.1 \%(2)$ & NS \\
\hline Deep Wound Complications & $1.9 \%(2)$ & $0 \%(0)$ & NS \\
\hline Injury to Surrounding Structure & $1 \%(1)$ & $0 \%(0)$ & NS \\
\hline DVT & $1 \%(1)$ & $0 \%(0)$ & \\
\hline
\end{tabular}

Overall complication rates were similar between the UBS and CBS groups $(19.8 \%, \mathrm{n}=21$ vs $12 \%, \mathrm{n}=4, \mathrm{p}-\mathrm{NS})$. Intraoperative complications were similar between groups $(4.8 \%, n=5$ vs $3.0 \%$, $\mathrm{n}=1, \mathrm{p}-\mathrm{NS}$ ) and included two cases of uterine atony (neither requiring a blood transfusion), one case of uterine rupture identified at the time of surgery, and three vacuum assistance in delivery of the infant in the UBS group and one vacuum assistance for delivery in the CBS group. Post-operative complications were also similar between UBS and CBS groups: Transfusions $(2.0 \%$, $\mathrm{n}=2$ vs $0 \%, \mathrm{n}=0, \mathrm{p}-\mathrm{NS}$ ); one after planned Cesarean hysterectomy for known placenta accreta who required a blood transfusion on postoperative day 2 and the other for symptomatic postoperative anemia; superficial wound complications (9.4\%, $\mathrm{n}=10 \mathrm{vs} .9 .4 \%, \mathrm{n}=3, \mathrm{p}-\mathrm{NS}$ ) which were drained and/or treated with antibiotics, except for one wound infection which required operative drainage in the UBS group; and endomyometritis, 
$(1.9 \% \mathrm{n}=2$ vs $0 \%, \mathrm{n}=0, \mathrm{p}-\mathrm{NS})$. In the UBS group, one patient had a suspected nerve entrapment as an injury to a surrounding structure, but was lost to follow-up. One patient developed a late pulmonary embolus on postoperative day 22 in the UBS group and was treated with anticoagulant therapy (Table 3).

\section{Discussion}

Our data demonstrates that the UBS is not inferior to the use of CBS during Cesarean section closure with respect to operative and post-operative complications and operative time, blood loss and length of hospital stay.

Since its introduction, there have been few studies addressing the use of barbed suture in gynecologic procedures [5] and in the setting of obstetric procedures, including Cesarean deliveries $[3,4]$. In one study using the barbed suture in laparascopic myomectomy $(n=138)$, the use of barbed suture demonstrated a significant reduction in mean duration of surgery and length of hospital stay, without significant differences in peri-operative complications and blood loss with the use of the barbed suture [1]. In contrast, while other studies found no significant reduction in total operative time, there was significant decrease in suturing time and blood loss [6,7]. With respect to those undergoing laparoscopic hysterectomy with and without robotic-assistance, the use of the barbed suture to close the vaginal cuff was also associated with a decrease in total operative time, blood loss, and length of hospital stay without increasing complications $[8,9]$ and significantly reduced postoperative vaginal bleeding and vaginal cuff dehiscence [10].

In the obstetric world, there has only been an isolated study regarding the use of the UBS during open surgery. Its use for dermal closure during Cesarean section was not associated with any significant differences with respect to incisional cosmesis, dermal closure time, and wound complications [3]. Our study is novel as it evaluated the use of barbed suture for closure of the entire Cesarean defect. Overall, there were no differences noted with respect to overall complications, blood loss, and operative time.

Our results should be interpreted with caution as there are several limitations including the retrospective design and our sample size did not provide adequate power to detect a difference in complication rates. Based on previous work of non-inferiority of $10 \%$ of UBS compared to CBS [3], our sample size provided $30 \%$ power to detect a difference and would have required 572 patients in each group to provide a power of at least $80 \%$. Regardless, our study demonstrates the technique of using the V-loc suture in cesarean section is being similar to more conventional suture types. Lastly, our study only followed outcomes for 6 weeks postpartum; as a result, long-term outcomes (such as scar formation, strength of the hysterotomy incision in subsequent pregnancies, and any unintentional effects on future fertility) with the barbed suture were not addressed.
A strength of our study is that all the Cesarean sections were performed or supervised by a single surgeon, minimizing operator variability and eliminating intervention bias. The difference in number between the subjects in which the V-loc was used compared to the number of more CBS used can be explained mostly by surgeon preference and using a single surgeon's patient group.

The potential benefits associated with the barbed suture include a looped or tabulated end, eliminating the need for knottying to secure the suture. Additionally, the suture is created by cutting barbs into the suture at equal distances, allowing the suture to self-anchor as it is passes through the tissue. This fixation prevents the suture from migrating and creates equal tension along the suture line, creating the effect of a continuous interrupted suture line, but without requiring multiple knots to be tied to achieve this security. The barbed suture is also monofilament, which may decrease the incidence of infection when compared to braided suture.

\section{Conclusion}

Our results suggest similar risk profiles using UBS compared CBS closures and may be considered as an adjunctive suture for closure of the hysterotomy, fascia and skin during Cesarean section based on the similar safety and efficacy between the suture types. Our study adds to the growing body of work on the barbed suture, though further studies including randomized trials would need to be performed to better evaluate the efficacy and safety of this method of closure as well as a cost analysis should also be considered.

\section{Declaration}

Ethics approval and consent to participate: This study was approved by the Wright State University, Miami Valley Hospital and United States Air Force Institutional Review Boards

Availability of data and material: The data that support the findings of this study are available from Dr. Keith Watson but restrictions apply to the availability of these data, which were used under license for the current study, and so are not publicly available. Data are however available from the authors upon reasonable request and with permission of Dr. Keith Watson.

\section{Author's contributions}

Vivina Napier, M.D. - Primary role in study design, data interpretation, and manuscript writing.

Rachel Warwar, M.D. - Data collection and manuscript writing and editing.

Keith Watson, M.D. - Surgeon performing Cesarean sections; provided charts for data collection.

Logan M. Havemann BS - Manuscript writing and editing.

Austin Findley, M.D. - Manuscript writing and editing. 
Rose A. Maxwell, PhD - Study planning and statistical analysis.

Steven R. Lindheim, M.D. MMM - Primary role in study planning, data interpretation, and manuscript editing.

\section{References}

1. Einarsson JI, Chavan NR, Suzuki Y, Jonsdottir G, Vellinga TT, et al. (2010) Use of bidirectional barbed suture in laparoscopic myomectomy: evaluation of perioperative outcomes, safety, and efficacy. J Minim Invasive Gynecol 18(1): 92-95.

2. Einarsson JI, Vellinga T, Twijnstra AR, Chavan NR, Suzuki Y, et al (2010) Bidirectional barbed suture: an evaluation of safety and clinical outcomes. J Soc Laparo endo Surg 14(3): 381-385.

3. Murtha AP, Kaplan AL, Paglia MJ, Mills BB, Feldstein ML, et al. (2006) Evaluation of a novel technique for wound closure using a barbed suture. Plast Reconstr Surg 117(6): 1769-1780.

4. Greenberg JA, Walden S, Hammer CM, Grazul-Bilska AT, Vonahme KA (2011) A comparison of barbed and smooth sutures for ovine cesarean delivery. Int J Gynecol Obstet 113(3):215-217.
5. Greenberg JA (2010) The use of barbed sutures in obstetrics and gynecology. Rev Obstet Gynecol 3(3): 82-91.

6. Angioli R, Plotti F, Montera R, Damiani P, Terranova C, et al. (2012) A new type of absorbable barbed suture for use in laparoscopic myomectomy. Int J Gynecol Obstet 117(3): 220-223.

7. Alessandri F, Remorgida V, Venturini PL, Ferrero S (2010) Unidirectional barbed suture versus continuous suture with intracorporeal knots in laparoscopic myomectomy: a randomized study. J Minim Invasive Gynecol 17(6): 725-729.

8. Nawfal AK, Eisenstein D, Theoharis E, Dahlman M, Wegienka G (2012) Vaginal Cuff Closure during Robotic-Assisted Total Laparoscopic Hysterectomy: Comparing Vicryl to Barbed Sutures. J Soc Laparo endo Surg 16(4): 525-529.

9. Siedhoff MT, Yunker AC, Steege JF (2011) Decreased incidence of vaginal cuff dehiscence after laparoscopic closure with bidirectional barbed suture. J Minim Invasive Gynecol 18(2): 218-23

10. Medina BC, Giraldo CH, Riano G, Hoyos LR, Otalora C (2014) Barbed Suture for Vaginal Cuff Closure in Laparoscopic Hysterectomy. J Soc Laparo endo Surg 18(1): 83-88.

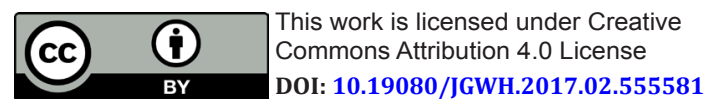

\section{Your next submission with Juniper Publishers will reach you the below assets}

- Quality Editorial service

- Swift Peer Review

- Reprints availability

- E-prints Service

- Manuscript Podcast for convenient understanding

- Global attainment for your research

- Manuscript accessibility in different formats

( Pdf, E-pub, Full Text, Audio)

- Unceasing customer service

Track the below URL for one-step submission https://juniperpublishers.com/online-submission.php 